04

\title{
Люминесценция кристаллов иттрий-алюминиевого граната С примесью ионов $\mathrm{Eu}^{2+}$
}

\author{
(C) Г.Р. Асатрян ${ }^{1}$, А.Б. Кулинкин ${ }^{1}$, С.П. Феофилов ${ }^{1}$, К.Л. Ованесян ${ }^{2}$, А.Г. Петросян ${ }^{2}$ \\ ${ }^{1}$ Физико-технический институт им. А.Ф. Иофрфе РАН, \\ Санкт-Петербург, Россия \\ ${ }^{2}$ Институт физических исследований НАН Армении, \\ Аштарак, Армения \\ E-mail: hike.asatryan@mail.ioffe.ru
}

(Поступила в Редакцию 3 августа 2016 г.)

Исследована люминесценция образцов иттрий-алюминиевого граната $\mathrm{Y}_{3} \mathrm{Al}_{5} \mathrm{O}_{12}$ : Eu,Si. Установлено, что люминесценция связана с ионами $\mathrm{Eu}^{2+}$, но не соответствует внутрицентровым $4 f^{6} 5 d^{1}-4 f^{7}$-переходам. Измерения времени жизни возбужденного состояния свидетельствуют о механизме люминесценции с участием состояний с переносом заряда.

Работа поддержана (грант РФФИ № 15-52-05040 Арм_а) и Госкомитом по науке Армении (грант 15RF-003).

DOI: 10.21883/FTT.2017.03.44156.323

\section{1. Введение}

Люминесценция примесных ионов редкоземельных металлов в диэлектрических кристаллах, обусловленная дипольно-разрешенными $5 d-4 f$-переходами, представляет большой интерес с точки зрения практических приложений. Так, иттрий-алюминиевый гранат с примесью церия $\mathrm{Y}_{3} \mathrm{Al}_{5} \mathrm{O}_{12}: \mathrm{Ce}^{3+}\left(\mathrm{YAG}: \mathrm{Ce}^{3+}\right)$ - хорошо известный люминесцентный материал, обладающий широкой электрон-фононной полосой излучения, обусловленной быстрыми $(65 \mathrm{~ns})$ разрешенными электродипольными $4 f^{0} 5 d^{1}-4 f^{1}$-переходами. Исследования YAG : $\mathrm{Ce}^{3+}$ привлекают большое внимание, так как этот материал широко используется как сцинтиллятор и люминофор. Особенно важным является его использование в светодиодных источниках белого света для преобразования синего излучения диода в красно-зеленую спектральную область. Интерконфигурационные $5 d-4 f$-переходы в ионах $\mathrm{Eu}^{2+}$ также приводят к эффективной люминесценции во многих кристаллах. Среди кристаллов с ионами $\mathrm{Eu}^{2+}$ наиболее изученным является флюорит $\mathrm{CaF}_{2}$, в котором наблюдается широкая полоса люминесценции в синей области. Достаточно хорошо изученным материалом является кристаллический $\mathrm{CaS}: \mathrm{Eu}^{2+}$, pacсматривавшийся в качестве красного люминофора [1]. Люминесценция ионов $\mathrm{Eu}^{2+}$ в диэлектрических матрицах представляет собой широкую электрон-фононную полосу, обусловленную быстрыми (время жизни возбужденного состояния порядка микросекунды) разрешенными электрон-дипольными излучательными переходами $4 f^{6}\left[{ }^{7} F_{0}\right] 5 d^{1}-f^{7}\left[{ }^{8} S_{7 / 2}\right][2]$.

Обширные спектроскопические исследования кристаллов с ионами $\mathrm{Eu}^{2+}$ в различных матрицах показали высокую чувствительность энергии самого нижнего возбужденного $4 f^{6}\left[{ }^{7} F_{0}\right] 5 d^{1}$-состояния к кристаллическому окружению: электрон-фононная полоса люминесценции может располагаться от синей до красной области спектра [2]. Исследование люминесценции ионов $\mathrm{Eu}^{2+}$ в новых матрицах представляет интерес с точки зрения поиска эффективных люминофоров, излучающих в разных областях видимого спектра. В [3] в кристаллах $\mathrm{Y}_{3} \mathrm{Al}_{5} \mathrm{O}_{12}: \mathrm{Eu}^{2+}$, соактивированных ионами $\mathrm{Si}^{4+}$, наблюдалось оптическое поглощение, связанное с ионами $\mathrm{Eu}^{2+}$, которое было приписано $4 f-5 d$-переходам. В то же время в [2] было высказано предположение, что это поглощение связано с переносом заряда с ионов $\mathrm{Eu}^{2+}$ на ионы $\mathrm{Si}^{4+}$.

В настоящей работе приводятся результаты исследований люминесценции кристаллов $\mathrm{Y}_{3} \mathrm{Al}_{5} \mathrm{O}_{12}$ : $\mathrm{Eu}$, соактивированных ионами $\mathrm{Si}^{4+}$.

\section{2. Детали эксперимента}

Кристаллы $\mathrm{Y}_{3} \mathrm{Al}_{5} \mathrm{O}_{12}: \mathrm{Eu}^{2+}$ выращивались методом вертикальной направленной кристаллизации в атмоcфере $\mathrm{Ar} / \mathrm{H}_{2}(5-10 \mathrm{vol} \%$ \%) с использованием высокочистых $(99.99 \%)$ компонентов - оксидов - и молибденовых контейнеров [4]. В качестве соактиватора, обеспечивавшего зарядовую компенсацию ионов $\mathrm{Eu}^{2+}$ (неизовалентно замещающих ионы $\left.\mathrm{Y}^{3+}\right)$, использовался $\mathrm{Si}^{4+}$. Кристаллы имеют глубокий синий цвет, обусловленный исследованным в [3] оптическим поглощением. Наличие ионов европия в двухвалентном состоянии в $\mathrm{Y}_{3} \mathrm{Al}_{5} \mathrm{O}_{12}$ подтверждено также методом электронного парамагнитного резонанса (ЭПР). Результаты подробных исследований спектров ЭПР ионов $\mathrm{Eu}^{2+}$ в иттрий-алюминиевом гранате опубликованы в работе [5].

Люминесценция образцов возбуждалась при помощи непрерывного полупроводникового лазера с длиной волны излучения $\lambda=405 \mathrm{~nm}$, твердотельных лазеров с диодной накачкой (DPSS) с $\lambda=473$ и $532 \mathrm{~nm}$ и гелий- 

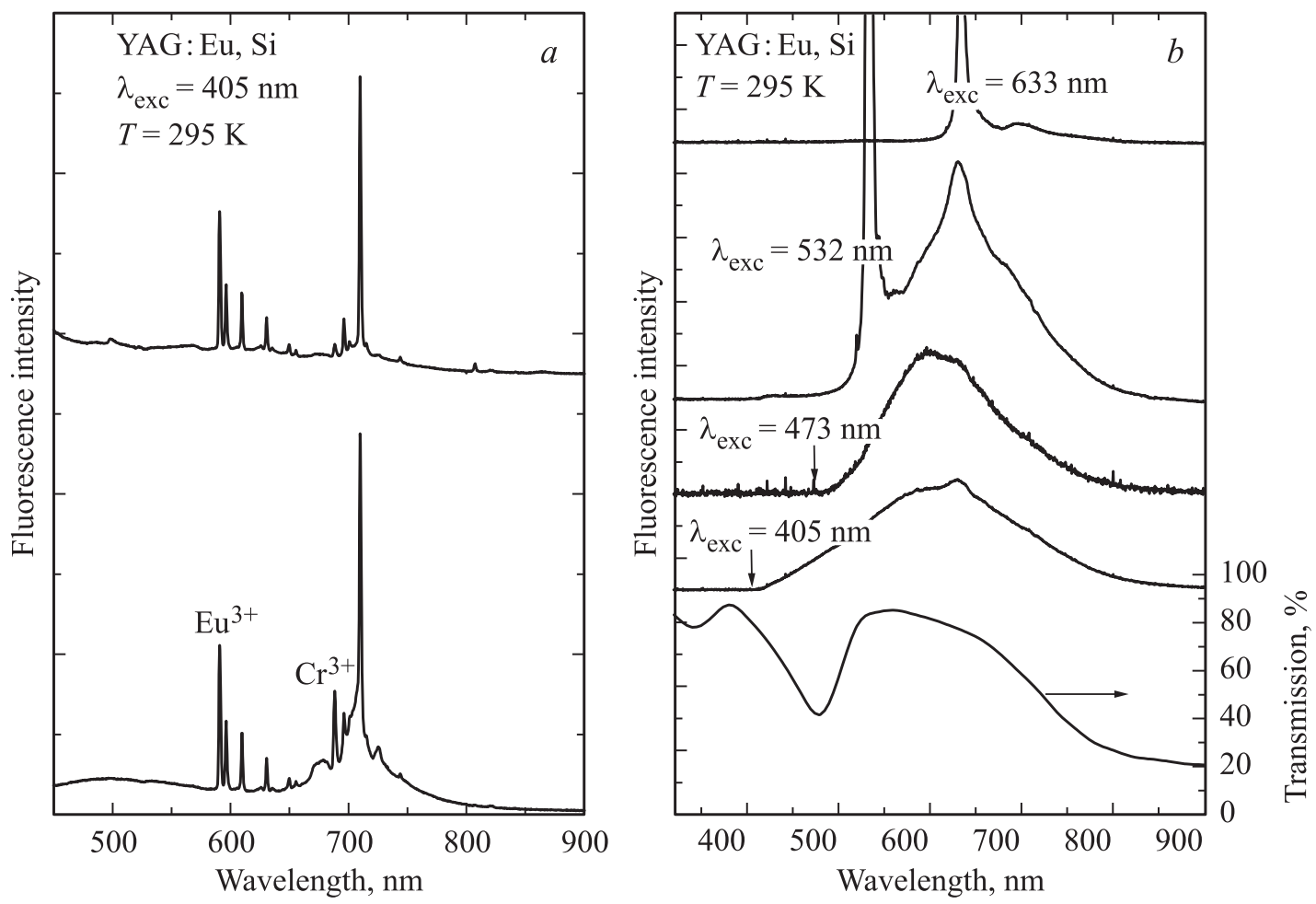

Рис. 1. Люминесценция кристаллов $\mathrm{Y}_{3} \mathrm{Al}_{5} \mathrm{O}_{12}: \mathrm{Eu}, \mathrm{Si}$ при различной длине волны возбуждающего света $\lambda_{\text {ехс }}$ и $T=295 \mathrm{~K}$. В различных образцах наблюдалась люминесценция: $a-\mathrm{Eu}^{3+}$ и $^{3+}, b-\mathrm{Eu}^{2+}$ (показан также спектр поглощения [3]).

неонового лазера с $\lambda=633 \mathrm{~nm}$, типичная мощность излучения составляла $30-80 \mathrm{~mW}$. Для измерения времени жизни люминесценции использовался импульсный твердотельный лазер с диодной накачкой ( $Q$-switched DPSS) с длиной волны излучения $532 \mathrm{~nm}$, длительностью импульса $10 \mathrm{~ns}$, частотой повторения импульсов $10 \mathrm{kHz}$ и средней мощностью $30 \mathrm{~mW}$. Спектры люминесценции регистрировались при помощи решеточного спектрометpa (разрешение $1 \mathrm{~nm}$ ) с CCD-детектором. Для измерения времени жизни люминесценции использовался двойной решеточный монохроматор (разрешение $0.4 \mathrm{~nm}$ ) с фотоумножителем, работающим в режиме счета фотонов, и применялась старт/стопная методика регистрации фотонов. Измерения проводились при комнатной температуре и температуре жидкого азота.

\section{3. Экспериментальные результаты и обсуждение}

Исследовалась люминесценция серии кристаллов $\mathrm{Y}_{3} \mathrm{Al}_{5} \mathrm{O}_{12}: \mathrm{Eu}, \mathrm{Si}$ с разными концентрациями ионов активатора и соактиватора и различающимися условиями роста. Обнаружено, что люминесценция образцов существенно различна: в значительной части образцов люминесценция отсутствовала, в части образцов наблюдалась узколинейчатая ${ }^{4} F_{n}-{ }^{5} D_{m}$-люминесценция ионов $\mathrm{Eu}^{3+}[6]$ и $\mathrm{Cr}^{3+}$ [7] (неконтролируемая примесь) (рис. 1,a), но в некоторых образцах удалось наблюдать интенсивную широкополосную люминесценцию (рис. $1, b$ ). Для сопоставления на рис. $1, b$ показан спектр поглощения из работы в [3]. На рис. 2 представлены спектры широкополосной люминесценции, полученные при $T=77 \mathrm{~K}$.

Спектры люминесценции (рис. 1, $b$ и 2) свидетельствуют о существовании нескольких различных люминесцирующих центров в $\mathrm{Y}_{3} \mathrm{Al}_{5} \mathrm{O}_{12}: \mathrm{Eu}, \mathrm{Si}$. Действительно, в спектре видны различные широкие компоненты, относительная интенсивность которых варьируется для различных длин волны возбуждения. Большая ширина полос указывает на их электрон-фононную природу, а спектральное положение позволяет предположить их связь с полосами поглощения, наблюдавшимися в [3]. Эти широкие полосы люминесценции естественно связать с ионами $\mathrm{Eu}^{2+}$.

Важным вопросом является выяснение природы широких полос люминесценции (а также поглощения) кристаллов $\mathrm{Y}_{3} \mathrm{Al}_{5} \mathrm{O}_{12}: \mathrm{Eu}, \mathrm{Si}$. С целью получения дополнительной информации об этой люминесценции были проведены измерения времени затухания люминесценции в полосах (рис. $1, b$ и 2) при импульсном возбуждении $\left(\lambda_{\mathrm{exc}}=532 \mathrm{~nm}, \Delta t=10 \mathrm{~ns}\right)$. Временно́е разрешение эксперимента позволяло зафиксировать времена затухания люминесценции с разрешением до $20 \mathrm{~ns}$. Результаты эксперимента показали, что затухание люминесценции на всех длинах волн внутри полосы люминесценции происходит со временем $\tau<20 \mathrm{~ns}$ (изменение люминесценции во времени полностью повторяло лазерный импульс). 


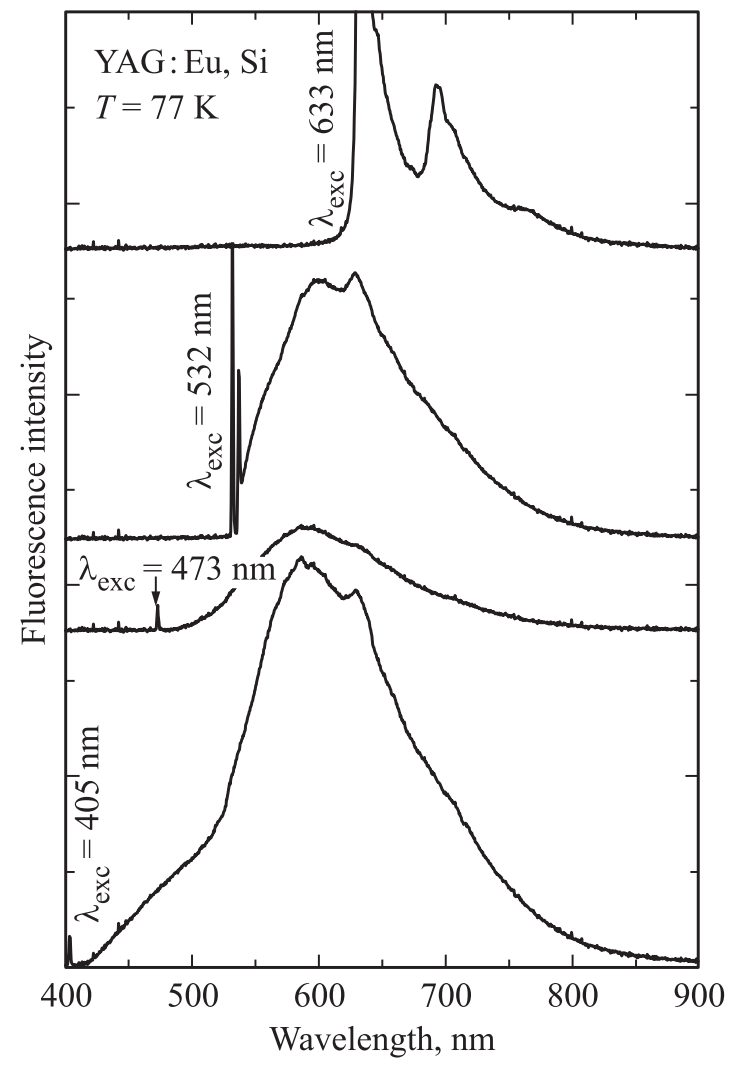

Рис. 2. Люминесценция кристалла $\mathrm{Y}_{3} \mathrm{Al}_{5} \mathrm{O}_{12}: \mathrm{Eu}, \mathrm{Si}$ при различной длине волны возбуждающего света $\lambda_{\text {ехс }}$ и $T=77 \mathrm{~K}$.

Быстрая (короче $20 \mathrm{~ns}$ ) кинетика люминесценции не согласуется с предположением о $4 f^{6} 5 d^{1}-f^{7}$-природе наблюдаемой люминесценции. Действительно, для $4 f^{6}\left[{ }^{7} F_{0}\right] 5 d^{1}-f^{7}\left[{ }^{8} S_{7 / 2}\right]$ люминесценции ионов $\mathrm{Eu}^{2+}$ характерно время жизни порядка микросекунды. Таким образом, предположение [2] о переносе заряда с ионов $\mathrm{Eu}^{2+}$ на ионы $\mathrm{Si}^{4+}$, отвечающем за электронные переходы, наблюдавшиеся в $\mathrm{Y}_{3} \mathrm{Al}_{5} \mathrm{O}_{12}: \mathrm{Eu}^{2+}, \mathrm{Si}^{4+}$, представляется более реалистичным. Действительно, полосы люминесценции и поглощения на рис. $1, b$ естественно сопоставить с одними и теми же переходами, а короткое время жизни характерно для состояний с переносом заряда. В пользу механизма люминесценции с переносом заряда свидетельствует также ее нестабильность от образца к образцу: люминесценция из состояний большого радиуса должна быть более чувствительной к реальной дефектной структуре кристалла.

\section{4. Заключение}

В образцах $\mathrm{Y}_{3} \mathrm{Al}_{5} \mathrm{O}_{12}: \mathrm{Eu}^{2+}, \mathrm{Si}^{4+}$ наблюдалась люминесценция, связанная с ионами $\mathrm{Eu}^{2+}$. Эта люминесценция не обусловлена $4 f^{6} 5 d^{1}-f^{7}-$ переходами в ионах $\mathrm{Eu}^{2+}$, ее более естественно отождествить с переходами с переносом заряда от ионов $\mathrm{Eu}^{2+}$. Вопрос о спектральном положении $4 f^{6} 5 d^{1}-f^{7}$-переходов в ионах $\mathrm{Eu}^{2+}$ в кристаллах YAG представляет значительный интерес и требует исследований образцов YAG:Eu с различной зарядово-компенсирующей соактивацией и образцов, выращенных в различных условиях.

\section{Список литературы}

[1] Y. Nakao. J. Phys. Soc. Jpn. 48, 534 (1980).

[2] P. Dorenbos. J. Lumin. 104, 239 (2003).

[3] Т.И. Бутаева, А.Г. Петросян, А.К. Петросян. Неорган. материалы 24, 430 (1988).

[4] А.А. Чернов, Е.И. Гиваргизов, Х.С. Багдасаров, В.А. Кузнецов, Л.Н. Демьянец, А.Н. Лобачев. Современная кристаллография. Наука, М. (1980). 337 с.

[5] В.А. Важенин, А.П. Потапов, Г.Р. Асатрян, Ю.А. Успенская, А.Г. Петросян, А.В. Фокин. ФТТ 58, 1573 (2016).

[6] H. Gross, J. Neukum, J. Heber, D. Mateika, T. Xiao. Phys. Rev. B 48, 9264 (1993).

[7] W. Nie, G. Boulon, J. Mares. Chem. Phys. Lett. 160, 597 (1989). 